\title{
Corrigendum to "Resistive index as a predictor of early failure of kidney transplantation"
}

Dai Sik Jeong, WeiJie He, Min Ho Shin, Nam Kyu Choi

Division of Hepato-biliary and Transplantation, Department of Surgery, Chosun University Hospital, Gwangju, Korea

In the article entitled "Resistive index as a predictor of early failure of kidney transplantation" [1], Funding/Support in ACKNOWLEDGMENTS was missing: This study was supported by research funds from Chosun University Hospital.

\section{REFERENCE}

1. Jeong DS, He W, Shin MH, Choi NK. Resistive index as a predictor of early failure of kidney transplantation. Korean J Transplant 2019;33:55-9. 